\title{
The Role of Spinal Cord Cyclic AMP in the Acoustic Startle Response in Rats
}

\author{
J. H. Kehne, D. I. Astrachan, ${ }^{1}$ E. Astrachan, J. F. Tallman, and M. Davis \\ Department of Psychiatry, Yale University School of Medicine, and Abraham Ribicoff Research Facilities of the \\ Connecticut Mental Health Center, New Haven, Connecticut 06508
}

Drugs thought to increase intracellular levels of cAMP were infused intrathecally into the subarachnoid space of the lumbar spinal cord, and the effects on the acoustic startle response in rats were measured. Intrathecal infusions of the cAMP analogs dibutyryl cAMP or 8-bromo cAMP (12.5-100 $\mu \mathrm{g})$ produced marked, dose-dependent increases in startle amplitude compared to the infusion of artificial cerebrospinal fluid (CSF). Local infusions of dibutyryl cAMP at more rostral levels of the spinal cord or brain failed to mimic the excitatory effect seen following lumbar intrathecal infusion. No excitation of startle was seen following intrathecal infusion of cAMP itself, ATP, 5'-AMP, or dibutyryl cGMP. A weak excitation of startle was seen following intrathecal, but not intraventricular, infusion of the water-soluble adenylate cyclase activator forskolin 7-deacetyl-7- $O$-hemisuccinic acid (forskolin-DHA; 5.0-100 $\mu \mathrm{g}$, in artificial CSF), whereas forskolin itself [0.01-200 $\mu \mathrm{g}$, in dimethyl sulfoxide (DMSO)] was without consistent effect. Finally, intrathecal infusion of the selective phosphodiesterase inhibitor Rolipram (12.5-200 $\mu \mathrm{g}$ ) produced a marked excitation of startle similar in magnitude to the effects produced by cAMP analogs.

The excitatory effects of intrathecally infused dibutyryl cAMP, 8-bromo cAMP, forskolin-DHA, or Rolipram support a functional link between spinal cord cAMP and the acoustic startle reflex. Possible sites of cAMP action on startle are discussed.

The cyclic nucleotide $3^{\prime}, 5^{\prime}$-adenosine cyclic monophosphate (cAMP) has been widely implicated as an intracellular second messenger in the peripheral and central nervous system (see Bloom, 1975; Daly, 1977). Despite the impressive biochemical and electrophysiological literature supporting this hypothesis, very few experiments have shown a direct association between alterations in cAMP levels and behavior. The purpose of the following study was to define possible sites of action of cAMP in the spinal modulation of a simple reflex behavior, the acoustic startle response in rats.

Acoustic startle is a short-latency reflex elicited by sudden, intense auditory stimuli. This reflex is mediated by a central

\footnotetext{
Received Feb. 11, 1986; revised May 12, 1986; accepted May 20, 1986.

We would like to thank Dr. James V. Cassella, Paul Giering, Alex Marek, and Leslie Fields for their many contributions at various stages of this resedrch, and Schering AG and Berlex Laboratories for supplying Rolipram. This research was supported by National Science Foundation Grant BNS-81-20476, National Institutc of Ncurological and Communicative Disorders and Stroke (NINCDS) Grant NS18033, and National Institute of Mental Health Research Scientist Development Award MH-0004 to M.D., Program Projects Grant Award MH-2514276, and the State of Connecticut. J.H.K. was a postdoctoral fellow, supported in part by Biological Sciences Training Grant MH-14276 and by National Institutes of Health Individual Fellowship MH-09200.

Correspondence should be addressed to John H. Kehne, Ph.D., Department of Psychiatry, Yale University School of Medicine, 34 Park St., New Haven, CT 06508.

${ }^{1}$ Present address: Department of Surgery, Division of Otolaryngology, Yale University School of Medicine, 34 Park St., New Haven, CT. 06508.

Copyright (C) 1986 Society for Neuroscience $0270-6474 / 86 / 113250-08 \$ 02.00 / 0$
}

neural circuit that consists of both brain stem and spinal cord components (Davis et al., 1982). The identities of the transmitters that are released at the various synapses of the startle circuit are not fully characterized. However, studies using direct drug infusion into the subarachnoid space of the lumbar spinal cord (intrathecal infusion) have shown that a number of neurochemical systems modulate startle at the level of the lumbar spinal cord (Astrachan and Davis, 1981; Davis and Astrachan, 1981; Gallager et al., 1983; Kehne and Davis, 1985; Kehne et al., 1981). Within the spinal cord, the amino acids glycine and GABA appear to functionally inhibit startle, whereas the monoamine transmitters serotonin and norepinephrine are facilitatory. Recent biochemical studies have provided evidence for a linkage between spinal norepinephrine and cAMP (Jones and McKenna, 1980a, b; Jones et al., 1984). If such a relationship exists, either for norepinephrine or for other spinal transmitters that are excitatory to acoustic startle, then pharmacological treatments that increase the generation of cAMP in the spinal cord should increase startle amplitude.

In the following study, several compounds that increase intracellular levels of cAMP were administered intrathecally and the resulting effects on startle amplitude were measured. The drugs tested were (1) the cAMP analogs dibutyryl cAMP and 8-bromo cAMP; (2) forskolin, a direct activator of adenylate cyclase (Seamon, 1985; Seamon and Daly, 1981a, b), and a water-soluble derivative forskolin, 7-deacetyl-7- $O$-hemisuccinic acid (forskolin-DHA), which also stimulates cAMP production in membrane preparations (K. Seamon, personal communication); and (3) Rolipram (ZK 62 711), a selective inhibitor of phosphodiesterase with minimal activity as an adenosine antagonist or reuptake blocker (Nemoz et al., 1985; Phillis and Wu, 1982; Schneider, 1984; Schwabe et al., 1976; Wachtel, $1982,1983 \mathrm{a}, \mathrm{b})$.

\section{Materials and Methods}

\section{Animals}

Sprague-Dawley rats (Charles River, Kingston facility) weighing 350$550 \mathrm{gm}$ were housed in groups of 5 in a colony room maintained on a 12:12 hr light-dark cycle. Food and water were available ad libitum.

\section{Surgery}

All surgeries were carried out under halothane (Fluothane) anesthesia, with the rats secured in a Kopf stereotaxic instrument. Following surgery, rats were housed individually and allowed to recover for at least $4 \mathrm{~d}$ before beginning behavioral testing.

Methods for design and implantation of intracerebroventricular (i.c.v.) catheters were described previously (Kehne et al., 1981). Methods of implantation of intrathecal catheters were modified from previously described procedures (Astrachan and Davis, 1981; Kehne et al., 1981; Yaksh and Rudy, 1976). The standard intrathecal catheter used for drug infusion into the lumbar subarachnoid space was composed of an 8.5 $\mathrm{cm}$ length of PE-10 tubing, fused to a $3 \mathrm{~cm}$ length of PE-20 tubing. In some experiments, the length of the PE-10 portion of the catheter was 
varied $(4.5$ or $10.5 \mathrm{~cm}$ ) to assess possible drug effects in other regions of the spinal cord. Prior to cutting the catheter to length, the PE-10 portion of the catheter was stretched in boiling water to reduce its outer diameter and thereby lesson the likelihood that catheter implantation would produce compression of the spinal cord. To prevent subsequent shrinkage, the catheters were hardened immediately after boiling by immersion in cold water. For implantation, a standard Kopf rodent stereotaxic instrument was modified such that the arms of the instrument were elevated $14 \mathrm{~cm}$ above its base. Following anesthetization, the head of the rat was secured between blunt ear bars and the mouth positioned over the incisor bar. The body of the rat was then placed in a standing position such that the axis of the spinal column was perpendicular to the axis of the head. The back of the skull was then surgically exposed and a $19 \mathrm{gm}$ hypodermic needle was used to puncture a hole through the atlanto-occipital membrane that overlies the cisterna magna. The tip of the PE-10 portion of the intrathecal catheter was carefully inserted through the hole, then slowly snaked down the dorsal surface of the spinal cord in the subarachnoid space. During catheter insertion, occasional deviations of the tip of the catheter from the dorsal surface of the cord were indicated by muscle twitching (presumably due to mechanical stimulation of the spinal roots). At the first sign of such activity, the catheter was slightly retracted and the axis of the body was manipulated to avoid any further muscle twitching (indicative of spinal cord or root damage). The PE-20 portion of the intrathecal catheter was then secured to skull screws with fast-drying Loctite adhesive, and a piece of plastic straw (approximately $1 \mathrm{~cm}$ in length) was inserted over the PE-20 catheter, cemented to the skull screw, and filled with Silastic $732 \mathrm{RTV}$ adhesive/sealant, providing a protective collar for the catheter. These procedures resulted in implanted rats that were healthy and virtually indistinguishable from unoperated controls. The occasional rats that showed motor impairments from the operation were not used.

Intracisternal (i.c.) catheters were composed of $4 \mathrm{~cm}$ and $4 \mathrm{~mm}$ lengths of PE-20 polyethylene tubing, joined by a $4 \mathrm{~mm}$ length of 26 -gauge tubing bent at a right angle. The $4 \mathrm{~mm}$ PE-20 tubing butted against a $3 \times 3 \mathrm{~mm}$ section of rubber band (which served as a gasket). The catheter (secured in a stereotaxic arm parallel to the back of the skull) was inserted through a hole punctured in the atlanto-occipital membrane into the cisterna magna until the gasket (which was coated with a thin film of Vaseline) made contact with the back of the skull and the membranes. With the gasket held firmly against the back of the skull (to ensure a tight seal), the catheter was secured with Loctite adhesive to skull screws.

Catheters made from Silastic tubing were implanted chronically in the left jugular vein, using previously described procedures (Axelson and Bruot, 1982). The catheters were externalized through a special cap fastened to the back of the skull and flushed daily to maintain patency.

At the conclusion of testing, catheter patency was checked by dyc infusion, and data from animals with faulty catheters were not included in the subsequent data analysis.

\section{Apparatus}

The apparatus used to measure startle amplitude has been described previously (Cassella and Davis, 1986; Kehne and Davis, 1985; Weiss and Davis, 1976). Briefly, 5 separate stabilimeters recorded the amplitude of the startle response. Each stabilimeter consisted of an $8 \times 15 \times$ $15 \mathrm{~cm}$ cage suspended between compression springs within a steel frame. Cage movement resulted in displacement of an accelerometer which generated a voltage proportional to the velocity of displacement. Startle amplitude, defined as the maximum accelerometer voltage that occurred during the first $200 \mathrm{msec}$ after the startle stimulus was delivered, was measured with a PDP-11 computer. The stabilimeters were housed in a dimly lit, ventilated, sound-attenuating chamber; each was $10 \mathrm{~cm}$ from a high-frequency speaker (Radio Shack Supertweeter). The startle stimulus was a $50 \mathrm{msec}$, variable-intensity burst of white noise having a rise-decay time of $5 \mathrm{msec}$. Background white noise, provided by a Grason-Stadler white noise generator, was $55 \mathrm{~dB}$. Sound level measurements were made with a General Radio Model 1551-C level meter (A-scale).

\section{Test procedure}

Because of large individual differences in baseline startle amplitudes but consistent startle amplitudes across days, we used a matching procedure to optimize the distribution of rats across different experimental groups. In this matching procedure, rats were placed in the startle cages and, 5 min later, were presented with 30 noise bursts (10 at each of 3 intensities: 95,105 , and $115 \mathrm{~dB}$ ) at a $20 \mathrm{sec}$ interstimulus interval. On the basis of the mean startle level across these 3 intensities, the rats were assigned to equivalent groups.

One day after matching, rats were placed in the startle cages and, 5 min later, were presented with 72 noise bursts $(105 \mathrm{~dB})$ at a, $20 \mathrm{sec}$ interstimulus interval. Immediately following this $24 \mathrm{~min}$ baseline period, the rats were infused with either the test drug or the drug vehicle. The rats were immediately returned to the startle cages and tested for an additional period of up to $100 \mathrm{~min}$. The length of the postinfusion test period, determined from pilot work, was chosen to include the entire duration of the drug effect on startle. Following testing, rats were returned to their home cages. Four days later, an identical test procedure was carried out, except that rats previously injected with the drug now received vehicle, and vice versa. Thus, each rat served as its own control with regard to the treatment (drug vs vehicle), whereas dose varied between rats. This "crossover" design was used interchangeably with a pure between-subjects design, in which rats received only 1 treatment (vehicle or a given dose of a drug) and were tested only once.

Statistical analysis involved ANOVAs using the change scorcs computed for each rat (the mean startle amplitude for the postinjection test minus the mean startle amplitude for the preinjection $24 \mathrm{~min}$ baseline period). Within-subject factors were included for data gathered using a crossover design.

\section{Drugs}

Dibutyryl cAMP (monosodium salt; Sigma) or 8-bromo cAMP (sodium salt; Sigma) was dissolved immediately before infusion in artificial cerebrospinal fluid $(5 \mathrm{~mm}$ potassium chloride, $130 \mathrm{~mm}$ sodium chloride, $1.25 \mathrm{~mm}$ sodium phosphate, $15 \mathrm{~mm}$ D-glucose, $24 \mathrm{~mm}$ sodium carbonate, $2 \mathrm{~mm}$ calcium chloride, and $2 \mathrm{~mm}$ magnesium sulfate). For i.c.v. infusions, only doses of up to $50 \mu \mathrm{g}$ were given, since other studies showed that higher i.c.v. doses were subconvulsant or convulsant (Kantak et al., 1981b). Forskolin-DHA (Calbiochem-Behring) was also dissolved in artificial cerebrospinal fluid (CSF). Forskolin-DHA was mixed and sonicated just prior to infusion. Forskolin (Calbiochem-Behring) and Rolipram, 4-(3-cyclopentyloxy-4-methoxy-phenyl)-2-pyrrolidone (Berlex Laboratories and Schering AG), were dissolved in dimethyl sulfoxide (DMSO). For all central infusions, the drugs were injected in a $10 \mu \mathrm{l}$ volume and flushed through the catheters with $10 \mu \mathrm{l}$ of artificial CSF. For intravenous infusions, drugs were administered in a volume of $0.1 \mathrm{ml}$ of saline and flushed with $0.5 \mathrm{ml}$ of saline.

\section{Results}

\section{Dibutyryl and 8-bromo cAMP}

Following intrathecal infusion into the lumbar spinal cord subarachnoid space, dibutyryl cAMP (12.5-100 $\mu \mathrm{g})$ produced a marked, dose-dependent increase in the amplitude of the acoustically elicited startle response. Figure 1 shows the time course of the excitatory effect of $50 \mu \mathrm{g}$ dibutyryl cAMP as compared to artificial CSF infusion. The left panel of Figure 2 summarizes the dose-dependent excitation seen following intrathecal infusion. In marked contrast, the right panel of Figure 2 shows that local infusions of a range of doses of dibutyryl cAMP (12.5-50 $\mu \mathrm{g})$ into the lateral ventricle of the brain did not produce any excitation of acoustic startle. Further evidence for the anatomical specificity of the effects of dibutyryl cAMP can be seen in Table 1 . Thus, infusions of $50 \mu \mathrm{g}$ dibutyryl cAMP through intrathecal catheters terminating near the cervical/thoracic spinal cord junction $(4.5-\mathrm{cm}$-long catheters) or infusions through catheters implanted in the brain ventricular systems at the level of the brain stem (cisterna magna) or forebrain (lateral ventricle; data taken from Fig. 1) did not result in excitatory effects on startle amplitude. Partial excitation seen with the $10.5 \mathrm{~cm}$ catheter (sacral spinal cord) is probably attributable to the spread of the drug caudally to the lumbar spinal cord (see Yaksh and Rudy, 1976). A peripheral action of dibutyryl cAMP was not likely, since no excitation was seen in 2 rats given $50 \mu \mathrm{g}$ of dibutyryl cAMP intravenously or in 5 rats given $10 \mathrm{mg} / \mathrm{kg}$ i.p. (data not shown). Figure 3 shows that the excitatory effect of intrathecal infusion of dibutyryl cAMP was specific, since startle amplitude was not significantly altered by intrathecal infusion of cAMP, ATP, 5'AMP, or dibutyryl cGMP (100 $\mu \mathrm{g}$ each, all 


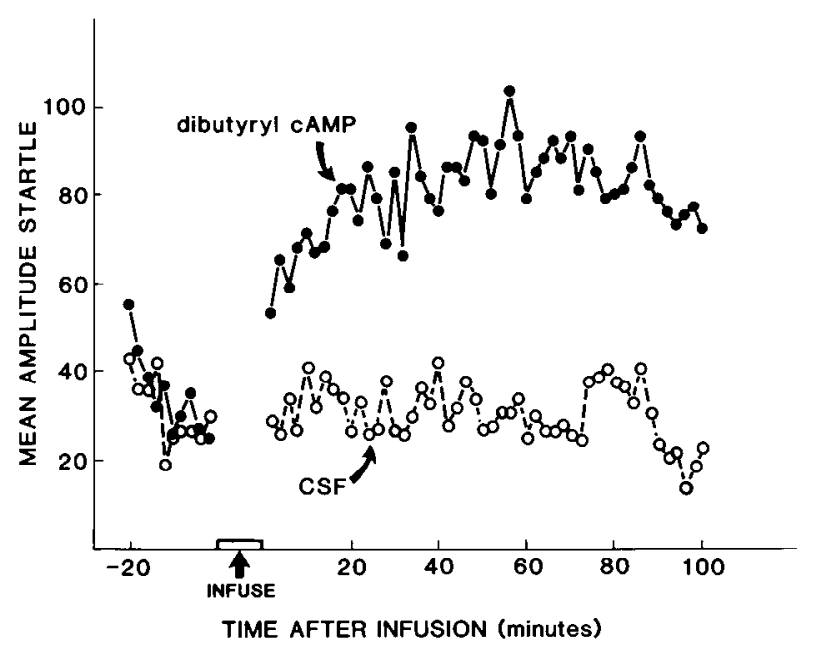

Figure 1. Effect of lumbar intrathecal infusion of $50 \mu \mathrm{g}$ dibutyryl cAMP on acoustic startle. Mean amplitude startle was measured before and after lumbar intrathecal infusion of $50 \mu \mathrm{g}$ of dibutyryl cAMP (closed circles) or artificial CSF (open circles). Each circle represents 2 min of testing (i.e., the mean of 6 consecutive startle scores). Each rat $(n=9)$ received both drug and artificial CSF treatments in test sessions separated by $4 \mathrm{~d}$.

dissolved in artificial CSF). 8-Bromo-5'AMP was also found to be ineffective (data not shown). Finally, consistent with the effects of bibutyryl cAMP, intrathecal infusion of 8-bromo cAMP, another CAMP analog, produced a marked, dose-dependent excitation of startle (Figs. 4 and 5).

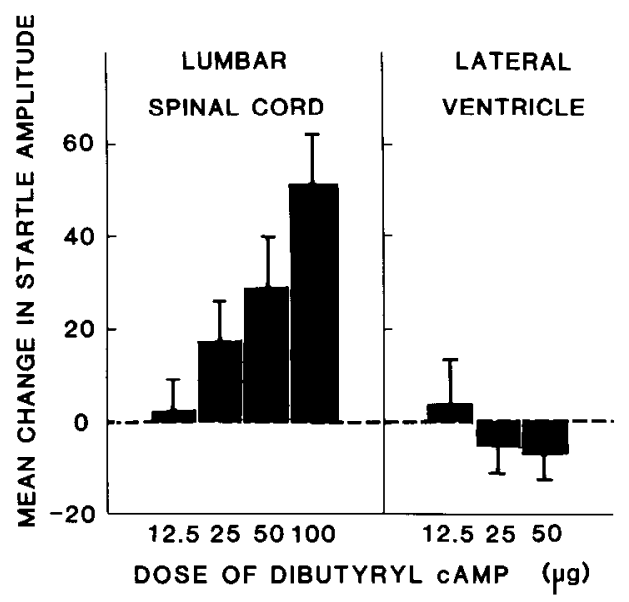

Figure 2. Dose-related effects of spinal (lumbar intrathecal) versus supraspinal (lateral ventricle) infusion of dibutyryl cAMP on startle. Each bar represents a "net change score" (i.e., a rat's drug change score minus its vehicle change score, where each change score is calculated by subtracting the $60 \mathrm{~min}$ postinfusion score from the $24 \mathrm{~min}$ preinfusion score). A positive score denotes a net excitatory drug effect. Independent groups of rats were used for each dose. Intrathecal doses: $12.5(n=10), 25.0(n=10), 50.0(n=9)$, and $100.0 \mu \mathrm{g}(n=10)$. Intraventricular doses: $12.5(n=5) ; 25.0(n=5)$; and $50.0 \mu \mathrm{g}(n=7)$. For the intrathecal data, a 2-way ANOVA on the change scores revealed an overall significant dibutyryl cAMP effect $(F(1,35)=4.45, p<0.001)$, a significant dose effect $(F(3,35)=6.52, p<0.001)$, and a significant dose $\times$ treatment interaction $(F(3,35)=6.52, p<0.001)$. Individual $t$ tests at each dose revealed a significant drug excitation at $25.0(t(9)=$ $2.89, p<0.05), 50.0(t(8)=3.08, p<0.05)$, and $100.0 \mu \mathrm{g}(t(9)=4.68$, $p<0.001)$. The effect of $100 \mu \mathrm{g}$ was significantly greater than that of $12.5 \mu \mathrm{g}(t(18)=3.63, p<0.01)$ or $25 \mu \mathrm{g}(t(18)=2.15, p<0.05)$, but did not significantly differ from the effect of $50 \mu \mathrm{g}(t<1)$. An ANOVA of the lateral ventricle scores revealed no significant main effects $(F<$ 1).

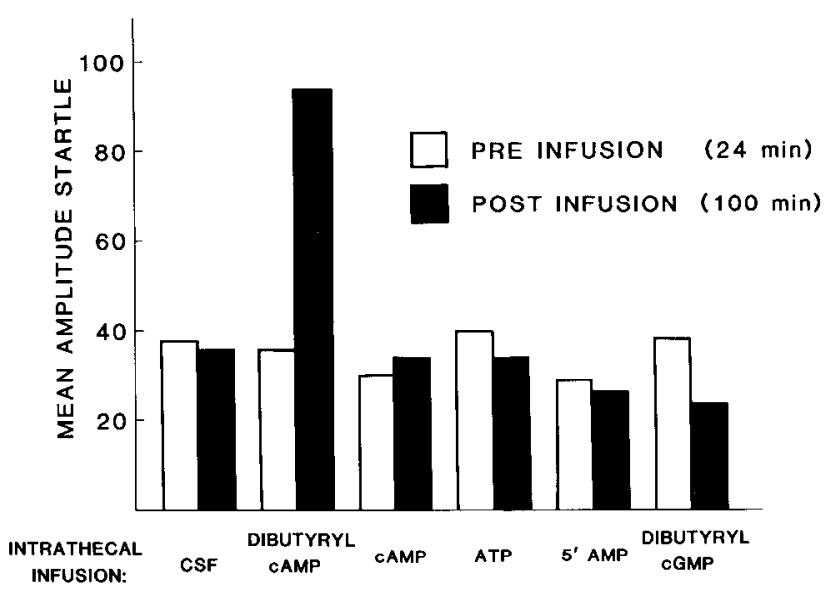

Figure 3. Specificity of intrathecal dibutyryl cAMP activation of startle. Mean amplitude startle was measured for $24 \mathrm{~min}$ before (open bars) and for $100 \mathrm{~min}$ after (closed bars) intrathecal infusion of vehicle (artificial CSF, $n=3)$, dibutyryl cAMP $(50 \mu \mathrm{g}, n=4), c A M P(100 \mu \mathrm{g}, n=$ 5), $A T P(100 \mu \mathrm{g}, n=5), 5^{\prime}-A M P(100 \mu \mathrm{g}, n=7)$, or dibutyryl $c G M P$ $(100 \mu \mathrm{g}, n=4)$. A between-subjects ANOVA using the change scores revealed an overall significant mean effect of treatment $(F(5,23)=10.35$, $p<0.001)$. Subsequent $t$ tests showed that, relative to artificial CSF treatment, only the dibutyryl cAMP effect was significant $(t(6)=3.34$, $p<0.01)$. The apparent depressant effect of dibutyryl cGMP approached statistical significancce $(t(6)=1.91,0.2<p<0.1)$.

\section{Forskolin and forskolin-DHA}

Given the marked excitatory effects of the cAMP analogs, it was surprising that intrathecal infusion of forskolin over a wide range of doses $(0.1-200 \mu \mathrm{g})$ failed to increase startle amplitude relative to DMSO vehicle infusion (Table 2). However, following intrathecal infusion of a water-soluble derivative, forskolin-DHA, a wcak excitation of startle amplitude (compared to the effects of the cAMP analogs) was seen (Table 2). The left panel of Figure

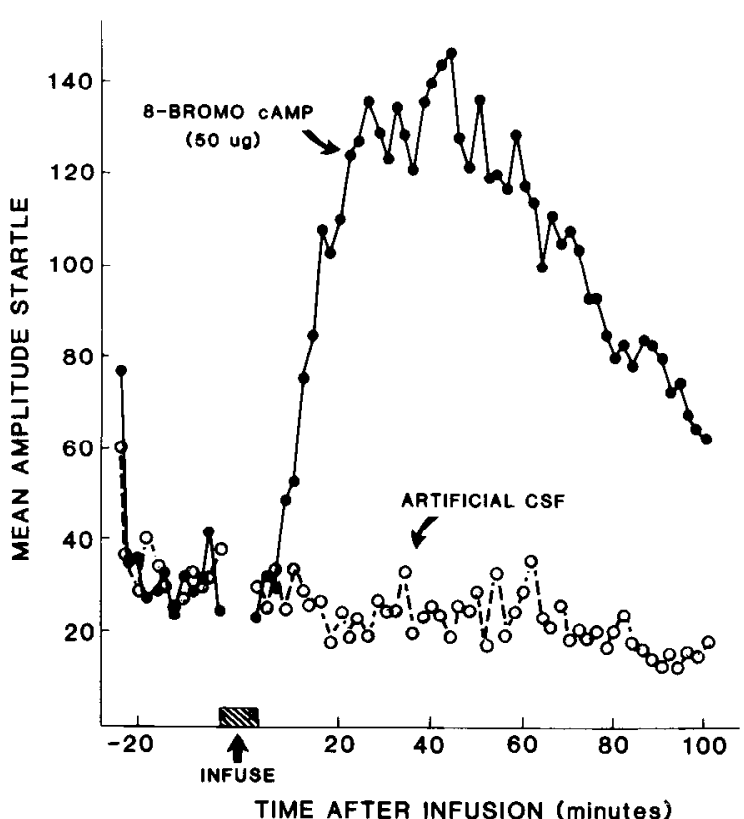

Figure 4. Effect of lumbar intrathecal infusion of $50 \mu \mathrm{g} 8$-bromo cAMP on acoustic startle. Mean amplitude startle was measured before and after lumbar intrathecal infusion of $50 \mu \mathrm{g} 8$-bromo-cAMP (closed circles) or artificial CSF (open circles). Each circle represents 2 min of testing (i.e., the mean of 6 consecutive startle scores). Rats received either drug $(n=5)$ or artificial CSF $(n=5)$ and were tested only once. 


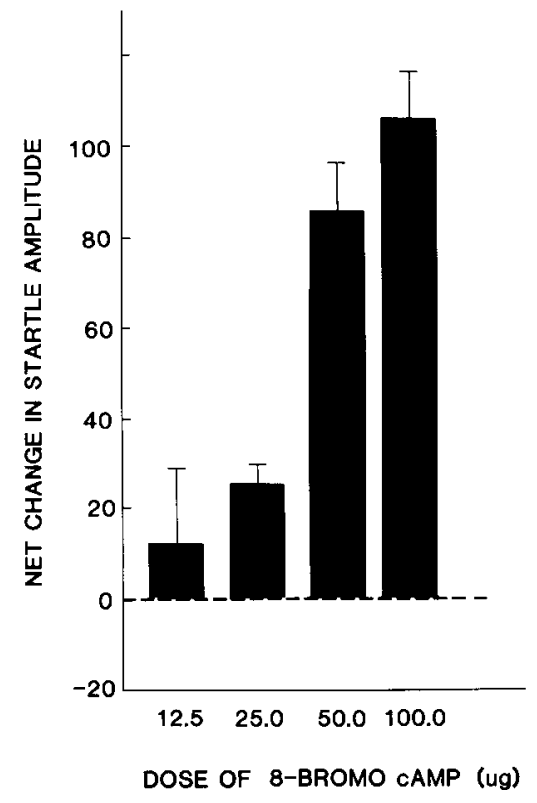

Figure 5. Dose-related effects of spinal (lumbar intrathecal) infusion of 8-bromo cAMP on startle. Each bar represents a "net change score" (i.e., drug change score minus mean vehicle change score) $\pm S E M$, where each change score is calculated by subtracting the 100 min postinfusion score from the 24 min preinfusion score. A positive score denotes a net excitatory drug effect. Independent groups of rats were used for each dose and vehicle (i.e., rats were tested only once). For all groups, $n=$ 5. A 1-way ANOVA on the change scores revealed an overall significant 8 -bromo cAMP drug effect $(F(4,20)=24.98, P<0.001)$. Individual $t$ tests at each dose, as compared to artificial CSF infusion, revealed a significant drug excitation at $25.0(t(8)=6.16, p<0.001), 50.0(t(8)=$ $8.98, p<0.001)$, and $100.0 \mu \mathrm{g}(t(8)=11.55, p<0.001)$. The effect of $25 \mu \mathrm{g}$ was significantly smaller than that of $50 \mu \mathrm{g}(t(11)=4.62, p<$ $0.01)$ or $100 \mu \mathrm{g}(t(8)=8.45, p<0.001)$. The difference between 50 and $100 \mu \mathrm{g}$ approached statistical significance $(t(1)=1.93, p=0.07)$.
6 shows the time course of the effect of $100 \mu \mathrm{g}$ forskolin-DHA infused intrathecally, and the right panel illustrates that a comparable dose given to the lateral ventricle produced no such excitation of startle. Table 3 shows that the startle-enhancing effects of 3 water-soluble compounds (dibutyryl cAMP, 8-bromo cAMP, and forskolin-DHA) were not diminished when these drugs were administered in DMSO rather than in artificial CSF. Thus, the lack of excitation seen with forskolin was probably not attributable to a solubility problem or to an interfering effect of DMSO.

\section{Rolipram}

Intrathecal infusion of the phosphodiesterase inhibitor Rolipram produced a marked, dose-dependent excitatory effect on startle, as compared to infusion of the DMSO vehicle (Figs. 7, 8). Figure 7 shows the time course of the excitatory effect of 200 $\mu \mathrm{g}$, while Figure 8 shows the dose-response relationship. Both in magnitude and time course, the effects of Rolipram were similar to those seen after intrathecal infusion of the cAMP analog 8-bromo cAMP.

\section{Discussion}

The purpose of this study was to assess the possible relationship between spinal cord cAMP and the acoustic startle response, using intrathecal infusion of drugs that are purported to increase intracellular levels of cAMP. The excitatory effects seen following intrathecal infusion of cAMP analogs (dibutyryl cAMP and 8-bromo cAMP), of the phosphodiesterase inhibitor Rolipram, or of the water-soluble derivative of forskolin all support the conclusion that increasing spinal cord levels of cAMP augment the amplitude of the startle reflex.

Substituted cAMP derivatives penetrate membranes more readily and are more resistant to phosphodiesterase than are their parent cyclic nucleotides (e.g., Hcnion ct al., 1967; Tsicn, 1977). These compounds activate cAMP-dependent protein kinases (Kuo et al., 1974; Miyamoto et al., 1969) and are behaviorally active when administered centrally (i.e., Gessa et al.,

Table 1. Anatomical specificity of dibutyryl cAMP excitation of startle

\begin{tabular}{|c|c|c|c|c|c|c|}
\hline $\begin{array}{l}\text { Mode of infusion } \\
\text { (target site) }\end{array}$ & $n$ & Treatment & $\begin{array}{l}24 \text { min } \\
\text { pre- } \\
\text { infusion }\end{array}$ & $\begin{array}{l}60 \mathrm{~min} \\
\text { post- } \\
\text { infusion }\end{array}$ & $\begin{array}{l}\text { Change } \\
\text { (post - pre) }\end{array}$ & $\begin{array}{l}\text { Net change } \\
\text { (drug - vehicle) }\end{array}$ \\
\hline \multicolumn{7}{|l|}{ Spinal cord } \\
\hline \multirow{2}{*}{$\begin{array}{l}\text { Intrathecal } 10.5 \mathrm{~cm} \\
\text { (sacral cord) }\end{array}$} & \multirow[t]{2}{*}{9} & Vehicle & 27.5 & 19.7 & -7.8 & \multirow{2}{*}{$+18.6^{*}(+68 \%)$} \\
\hline & & Drug & 26.9 & 37.8 & +10.8 & \\
\hline \multirow{2}{*}{$\begin{array}{l}\text { Intrathecal } 8.5 \mathrm{~cm} \\
\text { (lumbar cord) }\end{array}$} & \multirow[t]{2}{*}{9} & Vehicle & 30.0 & 23.4 & -6.6 & \multirow[t]{2}{*}{$+29.4^{*}(+90 \%)$} \\
\hline & & Drug & 33.6 & 56.4 & +22.8 & \\
\hline \multirow{2}{*}{$\begin{array}{l}\text { Intrathecal } 4.5 \mathrm{~cm} \\
\text { (cervical and thoracic cord) }\end{array}$} & \multirow[t]{2}{*}{7} & Vehicle & 27.2 & 21.6 & -5.6 & \multirow[t]{2}{*}{$+4.9(+18 \%)$} \\
\hline & & Drug & 26.7 & 26.0 & -0.7 & \\
\hline \multicolumn{7}{|l|}{ Brain } \\
\hline \multirow{2}{*}{$\begin{array}{l}\text { Intracisternal } \\
\text { (brain stem and cerebellum) }\end{array}$} & \multirow[t]{2}{*}{7} & Vehicle & 17.4 & 17.5 & +0.1 & \multirow[t]{2}{*}{$-2.9(-9 \%)$} \\
\hline & & Drug & 28.6 & 25.8 & -2.8 & \\
\hline \multirow{2}{*}{$\begin{array}{l}\text { Intraventricular } \\
\text { (forebrain) }\end{array}$} & \multirow[t]{2}{*}{7} & Vehicle & 21.7 & 19.0 & -2.7 & \multirow[t]{2}{*}{$-6.5 \quad(-35 \%)$} \\
\hline & & Drug & 21.2 & 12.0 & -9.2 & \\
\hline
\end{tabular}

Mean startle amplitude was measured prior to and following infusion of either $50 \mu \mathrm{g}$ of dibutyryl cAMP or artificial CSF. Infusions were made in separate groups of rats implanted with intrathecal catheters of different lengths $(4.5,8.5$, and $10.5 \mathrm{~cm}$ ) or implanted with catheters in the cisterna magna or lateral ventricle. A 2-way ANOVA on the change scores ( 60 min postinfusion minus 24 min preinfusion) revealed significant effects of dibutyryl cAMP $(F(1,34)=10.26$, $p<0.005)$, placement $(F(4,34)=3.16, p<0.025)$, and, importantly, a significant drug $\times$ placement interaction effect $(F(4,34)=2.91, p<0.05)$. Subsequent $t$ tests comparing the dibutyryl cAMP change score to the artificial CSF change score revealed significant excitatory effects in the $8.5 \mathrm{~cm}$ intrathecal catheter group $(t(8)=3.08, p<0.05)$ and in the $10.5 \mathrm{~cm}$ group $(t(8)=2.44, p<0.05)$. The stimulatory effect in the $10.5 \mathrm{~cm}$ group, because it is smaller in magnitude than the stimulation seen in the $8.5 \mathrm{~cm}$ group, is probably attributable to caudal diffusion of drug to the lumbar spinal cord.

$* p<0.05$. 


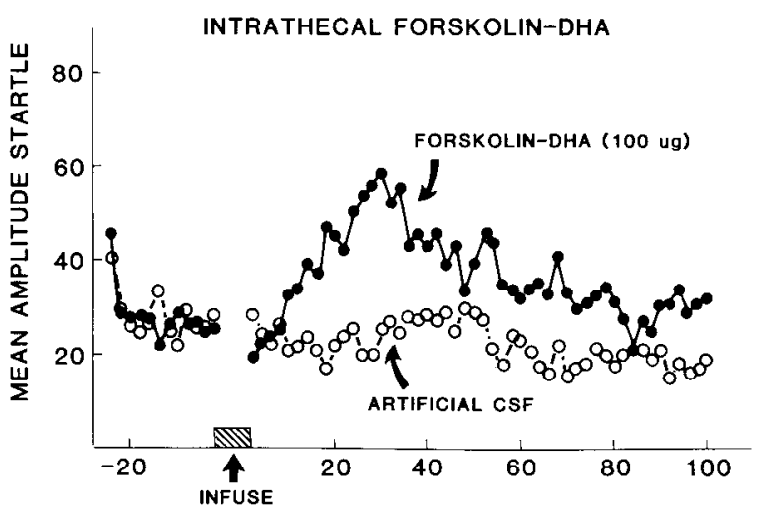

TIME AFTER INFUSION (minutes)

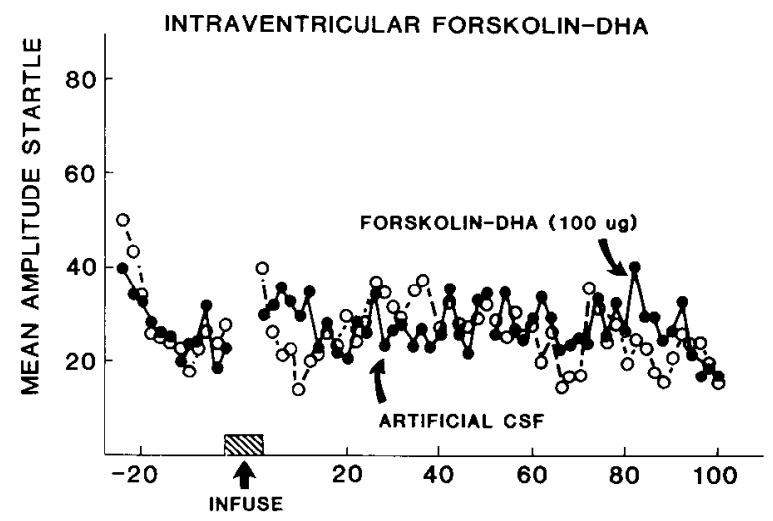

TIME AFTER INFUSION (minutes)

Figure 6. Effect of lumbar intrathecal infusion versus lateral ventricle infusion of $100 \mu \mathrm{g}$ forskolin-DHA on acoustic startle. Data represented as in Figure 1. Separate groups of rats implanted with either intrathecal catheters $(n=12$; data taken from Table 2$)$ or intraventricular catheters $(n=$ 8) were infused on separate test days with forskolin-DHA or artificial CSF, using a crossover design. Relative to artificial CSF infusion, forskolinDHA was excitatory following intrathecal infusion $(t(1)=3.57, p<0.005)$, but not following intraventricular infusion $(t<1)$.

1970; Herman, 1973; Kantak et al., 1981a, b). Following intrathecal infusion into the subarachnoid space of the lumbar spinal cord, dibutyryl cAMP or 8-bromo cAMP dose-dependently increased startle amplitude. Further experiments demonstrated anatomical specificity (the excitation was not attributable to metabolites or to other nonspecific changes).

Biochemical studics in intact and broken-cell preparations have provided abundant evidence that forskolin, a diterpene isolated from Coleus forskolii, produces a rapid and reversible stimulation of cAMP formation (Seamon and Daily, 1981a, b).
Forskolin-DHA, a water-soluble forskolin derivative, has more recently been shown to bc an effcctive (albeit 2-3 times less potent) activator of adenylate cyclase (K. Seamon, personal communication). Given the robust effects seen with either of the cAMP analogs, it was surprising to find that intrathecal infusions of adenylate cyclase activators produced either no excitation (forskolin) or a weak excitation (forskolin-DHA) of startle.

Although we do not have direct biochemical evidence that intrathecally infused forskolin was in fact activating spinal cord

\begin{tabular}{|c|c|c|c|c|c|c|}
\hline Dose $(\mu \mathrm{g})$ & $n$ & Treatment & $\begin{array}{l}24 \text { min } \\
\text { preinfusion }\end{array}$ & $\begin{array}{l}60 \text { min } \\
\text { postinfusion }\end{array}$ & $\begin{array}{l}\text { Change } \\
\text { (post - pre) }\end{array}$ & $\begin{array}{l}\text { Net change } \\
\text { (drug - vehicle) }\end{array}$ \\
\hline \multicolumn{7}{|c|}{ Forskolin $($ vehicle $=$ DMSO $)$} \\
\hline \multirow[t]{2}{*}{0.1} & 6 & Vehicle & 42.1 & 44.0 & +1.9 & $0.9(+2 \%)$ \\
\hline & & Drug & 38.6 & 41.4 & +2.8 & \\
\hline \multirow[t]{2}{*}{1.0} & 6 & Vehicle & 43.9 & 39.6 & -4.3 & $-2.3(-3 \%)$ \\
\hline & & Drug & 52.9 & 46.0 & -6.6 & \\
\hline \multirow[t]{2}{*}{10.0} & 7 & Vehicle & 29.5 & 31.6 & +2.1 & $-4.3(-13 \%)$ \\
\hline & & Drug & 29.5 & 27.3 & -2.2 & \\
\hline \multirow[t]{2}{*}{50.0} & 7 & Vehicle & 42.7 & 32.2 & -10.5 & $-0.4(-1 \%)$ \\
\hline & & Drug & 42.6 & 31.7 & -10.9 & \\
\hline \multirow[t]{2}{*}{100.0} & 8 & Vehicle & 48.0 & 41.7 & -6.9 & $+3.4(+5 \%)$ \\
\hline & & Drug & 39.7 & 36.2 & -3.5 & \\
\hline \multirow[t]{2}{*}{200.0} & 7 & Vehicle & 31.3 & 20.2 & -11.1 & $+2.0(+11 \%)$ \\
\hline & & Drug & 38.0 & 28.9 & -9.1 & \\
\hline \multicolumn{7}{|c|}{ Forskolin, 7-Deacetyl-7- $O$ hemisuccincic acid (vehicle $=$ artificial CSF) } \\
\hline \multirow[t]{2}{*}{25.0} & 14 & Vehicle & 34.7 & 31.8 & -2.9 & $+1.5(+5 \%)$ \\
\hline & & Drug & 40.1 & 38.7 & 1.4 & \\
\hline \multirow[t]{2}{*}{50.0} & 12 & Vehicle & 27.5 & 30.7 & +3.2 & $+8.1(+23 \%)$ \\
\hline & & Drug & 32.2 & 43.6 & +11.3 & \\
\hline \multirow[t]{2}{*}{100.0} & 12 & Vehicle & 28.2 & 22.2 & -3.7 & $+15.1 *(+53 \%)$ \\
\hline & & Drug & 28.6 & 17.2 & +11.4 & \\
\hline
\end{tabular}

Vehicle for forskolin was DMSO, and vehicle for forskolin-DHA was artificial CSF, Mean startle amplitude scores are averaged over the $24 \mathrm{~min}$ preinfusion period (i.e., 72 stimuli) or over the $60 \mathrm{~min}$ postinfusion period (180 stimuli). A 2 -way ANOVA (treatment, dose factors) of the forskolin change scores revealed no significant main or interaction effects $(F<1)$. ANOVA of the forskolin-DHA change scores revealed a dose effect that approached statistical significance $(F(2,37)=2.35,0.1<p<0.2)$, a significant drug effect $(F(1,37)=7.54, p<0.01)$, and a dose $\times$ drug interaction that approached statistical significance $(F(2,37)=1.70,0.1<p<0.2)$. Subsequent analyses of individual doses revealed significant drug excitation at the $100 \mu \mathrm{g}$ dose $(t(9)=3.71, p<0.005)$.

${ }^{*} p<0.005$. 


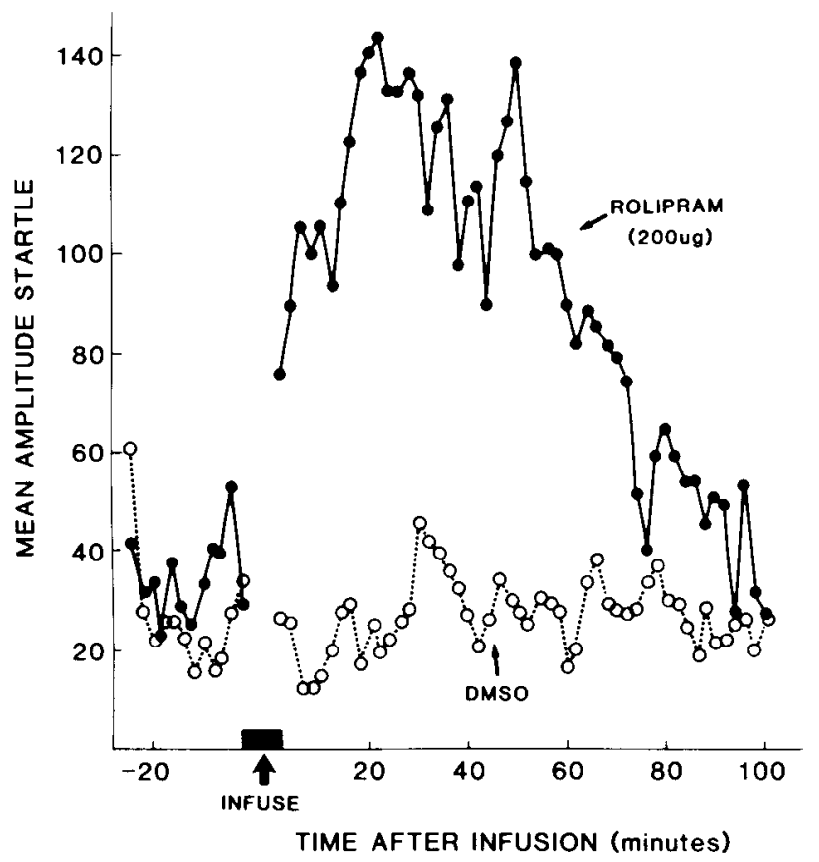

Figure 7. Effect of lumbar intrathecal infusion of $50 \mu \mathrm{g}$ Rolipram on acoustic startle. Mean amplitude startle was measured before and after lumbar intrathecal infusion of $50 \mu \mathrm{g}$ of Rolipram (closed circles) or vehicle (DMSO, open circles). Independent groups of rats were used for each dose and for the vehicle treatment (i.e., rats were tested only once).

adenylate cyclase, others have reported behavioral effects (locomotor depression; Barraco et al., 1985) and biochemical effects (activation of brain adenylate cyclase; Suzdak and Browne, 1985) following intraventricular forskolin infusion. Barraco et

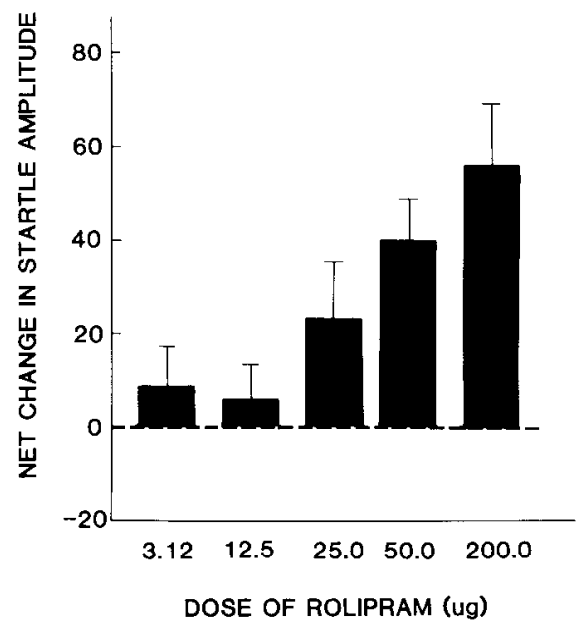

Figure 8. Dose-related effects of lumbar intrathecal infusion of Rolipram on startle. Each bar represents a "net change score" (i.e., drug change score minus mean vehicle change score) \pm SEM, where each change score is calculated by subtracting the 100 min postinfusion mean from the $24 \mathrm{~min}$ preinfusion score. Rats were tested only once; $n=5$ in cach group. A 1-way ANOVA revcaled an ovcrall significant cffect of Rolipram $(F(5,24)=8.02, p<0.001)$. Subsequent $t$ tests (as compared to DMSO-treated controls) revealed significant excitation at 50 $\mu \mathrm{g}(t(8)=4.80, p<0.01)$ and at $200 \mu \mathrm{g}(t(8)=4.19, p<0.005)$. The effect of $25 \mu \mathrm{g}$ was significantly smaller than that of $50 \mu \mathrm{g}(t(8)=3.63$, $p<0.01)$ or $200 \mu \mathrm{g}(t(8)=3.61, p<0.01)$. The difference between 50 and $200 \mu \mathrm{g}$ was not statistically significant, $(t(8)=1.06$, n.s.).

al. (1985) and Suzdak and Browne (1985) used 100\% DMSO for the forskolin vehicle (as was done in the present experiment). Furthermore, we found that other water-soluble compounds were still effective when DMSO was substituted for artificial CSF as the vehicle (see Table 3), making it unlikely that the use

I'able 3. Effects on startle of lumbar intrathecal infusion of water-soluble compounds dissolved in DMSO

\begin{tabular}{llcc} 
& & \multicolumn{2}{c}{ Vehicle } \\
\cline { 2 - 3 } Drug & & Artificial CSF & DSMO \\
\hline None & $n$ & 10 & 16 \\
& Pre $24 \mathrm{~min}$ & 31.5 & 34.6 \\
& Post $100 \mathrm{~min}$ & 28.6 & 31.0 \\
Dibutyryl cAMP & Change & $-2.9(-9 \%)$ & $-3.6 \quad(-10 \%)$ \\
$50 \mu \mathrm{g}$ & $n$ & 8 & 8 \\
& Pre $24 \mathrm{~min}$ & 27.9 & 33.2 \\
& Post $100 \mathrm{~min}$ & 70.9 & 77.8 \\
8 -Bromo cAMP & Change & $+43.0^{*}(+154 \%)$ & $+44.6^{* *}(134 \%)$ \\
$50 \mu \mathrm{g}$ & $n$ & 8 & 8 \\
& Pre $24 \mathrm{~min}$ & 33.6 & 27.1 \\
Forskolin-DHA & Post $100 \mathrm{~min}$ & 100.5 & 83.7 \\
$100 \mu \mathrm{g}$ & Change & $+66.9^{*}(+198 \%)$ & $56.6^{* *}(209 \%)$ \\
& $n$ & 8 & 8 \\
& Pre $24 \mathrm{~min}$ & 27.5 & 35.0 \\
& Post $100 \mathrm{~min}$ & 37.9 & 44.9 \\
& Change & $+10.4^{*}(+38 \%)$ & $+9.9^{* *}(+28 \%)$
\end{tabular}

Mean startle amplitude scores are averaged over the 24 min preinfusion ( 72 stimuli) period or over the 100 min period immediately following infusion (300 stimuli). Each cell represents independent groups of rats. An overall 2-way ANOVA on the change scores revealed a significant drug effect $(F(3,66)=26.70, p<0.001)$. The vehicle and drug $\times$ vehicle interaction effects were both nonsignificant $(F<1)$. Individual $t$ tests (drug vs appropriate vehicle group) revealed significant excitation of startle for each treatment $(p<0.01)$.

${ }^{*} p<0.01$ vs artificial CSF.

${ }^{* *} p<0.003$ vs DMSO. 
of DMSO per se masked an excitatory effect of forskolin on startle.

An alternative explanation for the weak effects of the adenylate cyclase activators was provided by the finding that intrathecal infusion of the phosphodiesterase inhibitor Rolipram produced a very marked excitatory effect on startlc. This cxcitation was very rapid in onset and comparable in magnitude to the effects seen with the cAMP analogs. Thus, it is possible that, in the spinal cord, there is a maximal or near-maximal turnover of cAMP. A combination of high basal adenylate cyclase activity (due, for example, to tonic activation of the receptors linked to adenylate cyclase) and a high level of endogenous phosphodiesterase activity would explain the functional findings that we have reported. Thus, adenylate cyclase activators would be weak or ineffective in altering startle, since adenylate cyclase activity would be near-maximal. On the other hand, alternative treatments (such as inhibiting phosphodiesterase, or "flooding" the cells with cAMP analogs) would bring out very marked excitatory functional effects, as we observed with the startle response.

Schneider (1984) noted that cAMP levels in various brain regions showed a rapid, dose-related rise following intravenous administration of Rolipram, which was attributed to a high rate of cAMP turnover in vivo. In preliminary experiments we have found that Rolipram increases startle following i.p. injection in a dose range approximately 10 -fold greater than that required for effects following intrathecal infusion. Importantly, the startle exitation induced by i.p. Rolipram occurs over the same dose range that was shown by Schneider (1984) to elevate cAMP levels in various brain regions after intravenous Rolipram infusion. These data indicate that, in the present study, the Rolipram doses that increased startle were within a range expected to produce dose-related inhibition of phosphodiesterase. Similar dose ranges of the cAMP analogs dibutyryl cAMP and 8-bromo cAMP produced comparable excitatory effects on startle, consistent with the conclusion that the observed behavioral effects were mediated through a specific effect on cAMP.

The present studies did not address the question of which receptors are coupled to cAMP in relationship to enhanced startle. Some candidates that have been shown to be positively coupled to adenylate cyclase include beta-adrenergic, A2 adenosine, prostaglandin $\mathrm{E} 2$, and vasointestinal peptide receptors (see Seamon and Daly, 1981, for a review). To date, the effects on startle of intrathecal infusion of agonists for these receptors have not been fully evaluated. It is known that spinal alpha-1 adrenergic receptor stimulation enhances startle amplitude (see Davis et al., 1984, for a review) and also increases cAMP levels in the spinal cord (Jones and McKenna, 1980a, b; D. I. Astrachan, J. H. Kehne, M. Davis, and J. F. Tallman, unpublished observations). However, recent evidence suggests that alpha-1 adrenergic receptor stimulation probably increases cAMP levels by an indirect action (Daly et al., 1980, 1981). For example, alpha- 1 adrenergic receptor stimulation increased cAMP levels in cortex by facilitating the cAMP-stimulating action of vasointestinal peptide (Magistretti and Schorderet, 1985). A growing literature indicates that the actions of alpha- 1 adrenergic receptors are mediated through other intracellular signals, such as stimulation of polyphosphoinositide turnover and/or modulation of calcium fluxes (e.g., Exton, 1981; Fain and GarciaSainz, 1980). In pinealocytes, alpha-1 adrenergic stimulation activates protein kinase $C$, which in turn potentiates cAMP accumulation produced by beta-noradrenergic receptor stimulation (Sugden et al., 1985).

Although the identity of the receptor(s) directly linked to cAMP is presently not known, biochemical studies suggest possible indirect mechanisms through which increases in spinal cord cAMP might increase the startle response. For example, pharmacologically induced increases in cAMP levels can augment the stimulated release of certain neurotransmitters, including norepinephrine and serotonin (e.g., Markstein et al., 1984; Schoffelmeer et al., 1985). However, neither intrathecal infusion of alpha-1 adrenergic or serotonergic antagonists, nor depletion of lumbar norepinephrine or serotonin alters the startle-enhancing effect of intrathecal dibutyryl cAMP (J. H. Kehne, D. I. Astrachan, E. Astrachan, J. F. Tallman, and M. Davis, unpublishcd observations). Increased cAMP levels have also been reported to facilitate the release of the excitatory amino acid glutamate (Dolphin and Archer, 1983). Recent studies in our laboratory suggest that an excitatory amino acid might be the neurotransmitter released at a spinal synapse of the startle neural circuit. Thus, elevated intracellular levels of cAMP in presynaptic nerve terminals might increase startle by amplifying the amount of excitatory amino acid released by the startle-eliciting stimulus. Furture studies will attempt to identify the receptor systems that carry out these interactions in vivo.

\section{References}

Astrachan, D. I., and M. Davis (1981) Spinal modulation of the acoustic startle response: The role of norepinephrine, serotonin, and dopamine. Brain Res. 206: 223-228.

Axelson, J. F., and B. C. Bruot (1982) An improved jugular cannulation procedure and cannula storage apparatus. Physiol. Behav. 29. 949-951.

Barraco, R. A., J. W. Phillis, and H. J. Altman (1985) Depressant effect of forskolin on spontaneous locomotor activity in mice. Gen. Pharmacol. 16: 521-524.

Bloom, F. E. (1975) The role of cyclic nucleotides in central synaptic function. Rev. Physiol. Biochem. Pharmacol. 74: 1-103.

Cassella, J. V., and M. Davis (1986) The design and calibration of a startle measurement system. Physiol. Behav. 36: 377-383.

Daly, J. W. (1977) Cyclic Nucleotides in the Nervous System, Plcnum, New York.

Daly, J. W., W. Padgett, Y. Nimitkitpaisan, C. R. Creveling, and K. L. Kirk (1980) Fluronorepinephrines: Specific agonists for the activation of alpha and beta adrenergic-sensitive cyclic AMP-generating systems in brain slices. J. Pharmacol. Exp. Therap. 212: 382-389.

Daly, J. W., W. Padgett, C. R. Creveling, D. Cantacuzene, and K. L. Kirk (1981) Cyclic AMP-generating systems: Regional differences in activation by adrenergic receptors in rat brain. J. Neurosci. 1: 4959.

Davis, M., and D. I. Astrachan (1981) Spinal modulation of acoustic startle: Opposite effects of clonidine and $d$-amphetamine. Psychopharmacology 75: 219-225.

Davis, M., D. S. Gendelman, M. D. Tischler, and P. M. Gendelman (1982) A primary acoustic startle circuit: Lesion and stimulation studies. J. Neurosci. 2: 791-805.

Davis, M., D. Astrachan, J. Kehne, R. Commissaris, and D. Gallager (1984) Catecholamine modulation of sensorimotor reactivity measured with acoustic startle. In Catecholamines: Neuropharmacology and Central Nervous System: Theoretical Aspects, E. Usdin, A. Carlsson, A. Dahlström, and J. Engel, eds., pp. 245-258, Alan R. Liss, New York.

Dolphin, A. C., and E. R. Archer (1983) An adenosine agonist inhibits and a cyclic AMP analogue enhances the release of glutamate but not GABA from slices of rat dentate gyrus. Neurosci. Lett. 43: 49-54.

Exton, J. H. (1981) Molecular mechanisms involved in alpha-1 adrenergic responses. Mol. Cell. Endocrinol. 23: 233-264.

Fain, J. N., and J. A. Garcia-Sainz (1980) Role of phosphatidylinositol turnover in alpha- 1 and of adenylate cyclase inhibition in alpha- 2 effects of catecholamines. Life Sci. 26: 1183-1194.

Gallager, D. W., J. H. Kehne, E. A. Wakeman, and M. Davis (1983) Develpmental changes in pharmacological responsivity of the acoustic startle reflex: Effects of picrotoxin. Psychopharmacology 79: 8793.

Gessa, G. L., G. Krishna, J. Forn, A. Tagliamonte, and B. B. Brodie (1970) Behavioral and vegetative effects produced by dibutyryl cAMP injected into different areas of brain. In Advances in Biochemical Psychopharmacology, Vol. 3, E. Costa and P. Greengard, eds., pp. 371-381, Raven, New York.

Henion, W. E., E. W. Sutherland, and T. H. Posternak (1967) Effects of derivatives of adenosine 3',5'-phosphate on liver slices and intact animals. Biochim. Biophys. Acta 148: 106-113.

Herman, Z. S. (1973) Behavioral effects of dibutyryl 3',5' AMP, nor- 
adrenalinc and cyclic $3^{\prime}, 5^{\prime}$ AMP in rats. Ncuropharmacology 12: 705709.

Jones, D. J., and L. F. McKenna (1980a) Alpha adrenergic receptor mediated formation of cyclic AMP in rat spinal cord. J. Cyclic Nucleotide Res. 6: 133-141.

Jones, D. J., and L. F. McKenna (1980b) Norepinephrine-stimulated cyclic AMP formation in rat spinal cord tissue slices. J. Neurochem. 34: 467-469.

Jones, D. J., O. F. Alcantara, and R. M. Ademe (1984) Supersensitivity of the noradrenergic system in the spinal cord following intracisternal injection of 6-hydroxydopamine. Neuropharmacology 23: 431-438.

Kantak, K. M., L. R. Hegstrand, and B. Eichelman (1981a) Influence of cyclic GMP on rodent aggressive behavior. Life Sci. 21: 13791385.

Kantak, K. M., L. R. Hegstrand, and B. Eichclman (1981b) Aggression-altering effects of cyclic AMP. Neuropharmacology 20:79-82.

Kehne, J. H., and M. Davis (1985) Central noradrenergic involvement in yohimbine excitation of startle: Effects of DSP4 and 6-OHDA. Brain Res. 330: 31-41.

Kehne, J. H., D. W. Gallager, and M. Davis (1981) Strychnine: Brainstem and spinal mediations of excitatory effects on acoustic startle. Eur. J. Pharmacol. 76: 177-186.

Kuo, J. F., E. Miyamoto, and P. L. Reyes (1974) Activation and dissociation of adenosine $3^{\prime}, 5^{\prime}$-monophosphate-dependent and guanosine 3',5'-monophosphate-dependent protein kinases by various cyclic nucleotide analogs. Biochem. Phamacol. 23: 2011-2021.

Magistretti, P. J., and M. Schorderet (1985) Norepinephrine and histamine potentiate the increases in cyclic adenosine $3^{\prime}: 5^{\prime}$-monophosphate elicited by vasoactive intestinal peptide in mouse cerebral cortical slices: Mediation by alpha- 1 adrenergic and $\mathrm{H}-1$ histaminergic receptors. J. Neurosci. 5: 362-368.

Markstein, R., K. Digges, N. R. Marshall, and K. Starke (1984) Forskolin and the release of noradrenalin in cerebrocortical slices. Naunyn Schmiedebergs Arch. Pharmacol. 325: 17-24.

Miyamoto, E., J. F. Kuo, and P. Greengard (1969) Cyclic nucleotidedependent protein kinases. III. Purification and properties of adenosine $3^{\prime}, 5^{\prime}$-monophosphate-dependent protein kinase from bovine brain. J. Biol. Chem. 214: 6395-6402.

Nemoz, G., A.-F. Prigent, M. Moueqqit, S. Fougier, O. Macovschi, and $H$. Pacheco (1985) Selective inhibition of one of the cyclic AMP phosphodiesterases from rat brain by the neurotropic compound Rolipram. Biochem. Pharmacol. 34: 2997-3000.

Phillis, J. W., and P. H. Wu (1982) The effect of various centrally active drugs on adenosine uptake by the central nervous system. Comp. Biochem. Physiol. (C) 72: 179-187.
Schncidcr, H. H. (1984) Brain cAMP response to phosphodiesterase inhibitors in rats killed by microwave irradiation or decapitation. Biochem. Pharmacol. 33: 1690-1693.

Schoffelmeer, A. N. M., G. Wardeh, and A. H. Mulder (1985) Cyclic AMP facilitates the electrically evoked release of radiolabelled noradrenaline, dopamine and 5-hydroxytryptamine from rat brain slices. Naunyn Schmiedebergs Arch. Pharmacol. 330: 74-76.

Schwabe, U., M. Miyake, Y. Ohga, and J. W. Daly (1976) 4-(3-Cyclopentyloxy-4-methoxyphenyl)-2-pyrrolidine (ZK 62711): A potent inhibitor of adenosine cyclic $3^{\prime}, 5^{\prime}$-monophosphate phosphodiesterases in homogenates and tissue slices from rat brain. Mol. Pharmacol. 12: $900-910$

Seamon, K. B. (1985) Activation of hormone-sensitive adenylate cyclase by forskolin. Drug Dev. Res. 6: 181-192.

Scamon, K. B., and J. W. Daly (1981a) Forskolin: A unique diterpene activator of cyclic AMP generating systems. J. Cyclic Nucleotide Res. 1: 201-224.

Seamon, K. B., and J. W. Daly (1981b) Forskolin: Unique activator in membranes and in intact cells. Proc. Natl. Acad. Sci. USA 78. 3363-3367.

Sugden, D., J. Vanecek, D. C. Klein, T. P. Thomas, and W. B. Anderson (1985) Activation of protein kinase C potentiates isoprenazline-induced cyclic AMP accumulation in rat pinealocytes. Nature 314:359361.

Suzdak, P. D., and R. G. Browne (1985) The effect of chronic in vivo infusion of forskolin on noradrenergic receptor sensitivity. Psychopharmacology 87: 464-467.

Tsian, R. W. (1977) Cyclic AMP and contractile activity in heart. In Advances in Cyclic Nucleotide Research, Vol. 8, P. Grcengard and G. A. Robison, eds., pp. 363-420, Raven, New York.

Wachtel, H. (1982) Characteristic behavioral alterations in rats induced by Rolipram and other selective adenosine cyclic $3^{\prime}, 5^{\prime}$-monophosphate phosphodiesterase inhibitors.

Wachtel, H. (1983a) Neurotropic effects of the optical isomers of the selective adenosine cyclic $3^{\prime}, 5^{\prime}$-monophosphate phosphodiesterase inhibitor rolipram in rats in-vivo. J. Pharm. Pharmacol. 35: 440444.

Wachtel, H. (1983b) Species differences in behavioral effects of Rolipram and other adenosine cyclic $3^{\prime}, 5^{\prime}$-monophosphate phosphodiesterase inhibitors. J. Neural Trans. 56: 139-152.

Weiss, G. T., and M. Davis (1976) Automated system for acquisition and reduction of startle response data. Pharmacol. Biochem. Behav. 4: 713-720.

Yaksh, T. L., and T. A. Rudy (1976) Chronic catheterization of the spinal subarachnoid space. Physiol. Behav. 17: 1031-1036. 